\title{
TECHNOLOGY AND SPECIALIST CARE FOR OLDER PATIENTS IN THE POST COVID-19 ERA
}

\author{
K. Dervan ${ }^{1}$, G. Mulkerrin ${ }^{2}$, T. McDonnell ${ }^{1}$, E.C. Mulkerrin ${ }^{1}$
}

\begin{abstract}
The COVID-19 pandemic poses a major challenge to delivering multi-disciplinary complex care for older patients. Modern technology can assist in providing such care. This article highlights efforts to bridge the "digital divide" between generations and addresses the beneficial impact telemedicine has on older people's lifestyles. Novel triage models for accessing emergency care which were successful for patients of all age groups including those over 65 years are described. Moreover, innovative successful approaches to the outpatient assessment of older patients with complex chronic health conditions using telemedicine are highlighted. Furthermore, innovative solutions piloted in remote areas of Australia offer promise for telemedicinelead remote assessment of older patients, and the results are encouraging compared to in-person consultations. The experience with a General Practitioner (GP)/specialist online real-time interaction model for remote management of HF in mainly older people has also been encouraging. The use of telemedicine in falls prevention has produced impressive results in high-risk older patients albeit with some ambivalence from older participants. Virtual reality rehabilitation programmes have produced better physical outcomes than traditional rehabilitation programmes. Furthermore, telerehabilitation for chronic obstructive pulmonary disease (COPD) and HF have shown to be both feasible and effective. To maximise their benefits in the difficult post-COVID-19 period, technologies must be embraced by both physicians and older patients. Online community care platforms discussed have demonstrated a positive, tangible impact on the lifestyle of the older generation. Furthermore, educational guidelines can assist in implementing the fundamentals of telemedicine, but for the widespread successful and safe integration of these services, adoption of regulatory frameworks with a focus on ethical issues of telehealth is imperative.
\end{abstract}

Key words: COVID-19, aging, technology, virtual assessment, telemedecine.

\section{Introduction}

Since January 2020, a seismic shift has occurred in the way in which healthcare providers, patients, and the wider community interact with one another and the world around them. The outbreak of novel coronavirusassociated acute respiratory disease, known as COVID-19 is a "once-in-a-century pandemic" (1). Older patients, especially those with significant co-morbidities are at increased risk of severe disease and the cascade of associated complications, including disability and death (2). Strict social distancing measures have been implemented, while hospitals minimise in-person office visits in a bid to decrease the potential risk of cross-contamination. Dr. Marjory Warren the mother of British geriatric medicine formulated the early principles of Geriatric Medicine and, almost 70 years on,

1. Department of Geriatric Medicine, University Hospital Galway, Republic of Ireland; 2. Department of Neurology, National Hospital for Neurology and Neurosurgery, Queen's Square, London, United Kingdom

Corresponding Author: Dr. K Dervan, Department of Geriatric Medicine, University Hospital Galway, Republic of Ireland- killiandervan@gmail.com her teachings remain valid today (3). The importance of multidisciplinary teams, attention to diverse issues (medical, social, and functional), and active involvement of the older person in their clinical progress is paramount. The recent measures implemented in response to COVID-19 have added significant strain to these services (4), whilst also having a negative knock-on effect on older people's livelihood. Below strategies enabling technology to assist in the provision of specialist care to older patients in the post-COVID-19 pandemic era are discussed.

\section{Bridging the "Digital-Divide"}

Despite barriers to technology for older people, the current pandemic may act as a catalyst for bridging the digital divide, as older people have become more digitally connected, with many partaking in "Zoom" calls to see family and friends. Interestingly, the proportion of people using the internet aged 65 years or older has been rapidly increasing in recent years, with $80 \%$ of people aged 65-74 having used the internet in the previous 3 months (5). While a level of ambivalence 
amongst the older population regarding new technologies is understandable, numerous studies have reported high satisfaction rates with telemedicine (6). Older patients have reported a positive impact on their livelihoods, with an increased sense of well-being and safety, along with improvements in social cohesion thanks to online community care platforms (7). Furthermore, a study focussing on barriers to interacting with technology noted apprehension about the lack of clarity in the support and instructions provided. Despite this, most participants were eager to adopt new technology and willing to learn (8). To bridge the digital divide, EU initiatives like the "Grandparents \& Grandchildren Project", aim to encourage the younger generation to help and provide reassurance, in an attempt to improve digital literacy amongst older people (9). Whilst further research is necessary to successfully negotiate the "bridge", the above findings suggest significant progress and a positive attitude towards new technologies with a beneficial impact on lifestyle in the older population.

\section{Role of Telemedicine}

The unprecedented emergence of COVID-19 has transformed current clinical practice and now more than ever it is imperative to explore alternative options for providing specialist care in the future. Of particular importance in the case of older patients is ensuring that the person consents to their involvement in the virtual assessment process. Indeed a strong regulatory framework for digital health applications, processes, and software such as that of the US Food and Drug Administration should be adopted internationally. (10)

\section{Acute Care}

A "Forward Triage Model" - whereby patients are stratified before arrival in the Emergency Department (ED) with the use of smart devices or webcam-enabled computers, can act as a central strategy for surge control amidst a global pandemic. It focuses on efficient screening, is patient-centred, and conducive to selfquarantine measures, thus protecting patients, clinicians, and the community from exposure (11). An example of a similar successful system is the "ETHAN Project" in Houston, Texas (12). This initiative incorporates telecommunications technology to triage patients with non-life-threatening illnesses, who were being attended by emergency medical services (EMS) via telemedicine with an ED Physician. Whilst this study primarily focussed on EMS utilization and outcomes, patients in the study reported an $88 \%$ overall satisfaction rate with telemedicine-enabled EMS response. Furthermore, there was a significant reduction in ED ambulance transfers from $74 \%$ to only $18 \%$ and there was a 44 -minute reduction for the EMS unit back in-service time, resulting in two-fold greater productivity (12). Although further research is needed, it is worthwhile noting that patients $>65$ years old were included in the above study, an important factor for consideration when determining how clinicians can help provide specialist care with the use of technology to older patients during and post-COVID-19.

\section{Outpatient Assessments}

Providing outpatient services to an older cohort of patients is often difficult due to the complexity of their healthcare needs and adverse outcomes are common after discharge from ED (13). Some benefits of telemedicine for older patients are already documented (14). Early studies found that video conference-enabled telemedicine was as accurate as in-patient clinical examination for establishing a diagnosis of dementia (15). Additionally, patients reported a high degree of satisfaction and a willingness to participate in telemedicine-enabled clinical care in the future (15). Furthermore, at-home telemonitoring of chronically ill patients has been shown to have a positive impact on healthcare expenditure, the number of hospital admissions, reduction in length of stay(LOS) in hospital, and most importantly a reduction in mortality (16). Similarly, a 2015 Cochrane Systematic Review demonstrated similar health outcomes for patients with chronic health conditions including HF and DM when comparing telehealth-enabled remote monitoring and videoconferencing to in-person or telephone visits (17). Remaining independent and living in one's own home is often a key desire of older patients; outpatient virtual assessments facilitate this and could positively influence an older person's manner of living.

A recent pilot study in Western Australia compared the effectiveness of two alternative geriatrician models of care; the tele-geriatric service (TGS) and visiting geriatrician (VG) (18). In this study, GPs were encouraged to refer patients early during the course of symptom evolution, which subsequently translated into improved care coordination and slower disease progression. Furthermore, whilst both TGS and VG had similarly reduced rates of health service use, a higher volume of patients across a broader geographical area and improved waiting list management occurred using TGS. Consequently, TGS reduced avoidable hospitalisations and subsequent health deterioration (18).

Another key area where technology is applicable to healthcare is in the role of virtual consultations (VC), multidisciplinary meetings, and rehabilitation, with VC having been rapidly deployed in response to COVID-19 (19). The success of VC has also been demonstrated with the implementation of a GP-specialist on-line, real-time interaction for optimal management of outpatients with HF. Analysis of outcomes of this innovative approach shows a very positive impact on the provision of HF care in the community with high acceptability of its (mainly older) users, with only $17 \%$ requiring subsequent review in OPD (20). 
Table 1

Potential technological modalities for older patient assessments

\begin{tabular}{|c|c|c|}
\hline Setting & Summary & Reference \\
\hline \multirow[t]{3}{*}{$\begin{array}{l}\text { Bridging the "Digital } \\
\text { Divide" }\end{array}$} & $\begin{array}{l}\text { Vincent et al. - } \\
\text { - Tele-surveillance for the elderly had high satisfaction rates whilst also substantially } \\
\text { decreasing the psychological burden on caregivers. }\end{array}$ & (6) \\
\hline & $\begin{array}{l}\text { Willard et al. - } \\
\text { - Online community care platforms contribute to social participation and the self- } \\
\text { management competencies of frail older adults. }\end{array}$ & (7) \\
\hline & $\begin{array}{l}\text { Vaportzis et al. - } \\
\text { - Older adults were eager to adopt new technologies and willing to learn. }\end{array}$ & $(8)$ \\
\hline Acute Care & $\begin{array}{l}\text { Langabeer et al. - } \\
\text { - "ETHAN Project" - mobile telehealth-enabled emergency services were effective at } \\
\text { reducing unnecessary ED ambulance transports and increasing service productivity. }\end{array}$ & (12) \\
\hline Outpatient Assessments & $\begin{array}{l}\text { Celler et al. - } \\
\text { - At-home telemonitoring of chronically ill patients showed a positive impact on } \\
\text { health care expenditure, the number of admissions to hospital, and LOS as well as a } \\
\text { reduction in mortality. } \\
\text { Lillicrap et al. - } \\
\text { - Tele-geriatric services resulted in improved care coordination, reduced avoidable } \\
\text { hospitalisations, and subsequent health deterioration. } \\
\text { Gallagher et al. - } \\
\text { - Virtual consultations had a positive impact on the provision of heart failure care in } \\
\text { the community. }\end{array}$ & $(21)$ \\
\hline Rehabilitation & $\begin{array}{l}\text { Howard et al. - } \\
\text { - Virtual reality rehabilitation programmes are more effective than traditional } \\
\text { rehabilitation programmes for physical outcomes. }\end{array}$ & (25) \\
\hline Potential Barriers & $\begin{array}{l}\text { Langarizadeh et al. - } \\
\text { - Attention to ethical issues in telemedicine guarantees a safer use of the services. }\end{array}$ & $(30)$ \\
\hline
\end{tabular}

\section{Rehabilitation}

Falls are a common presenting complaint of older people both from the community and $\mathrm{NH}$, occurring in up to $30 \%$ of that population. Recent studies have shown that a telerehabilitation home-based programme, with integrated tele-surveillance, is feasible and effective in preventing falls in older patients with a high risk of falling (21), yet there remains a level of ambivalence among older participants around the utility of technology and their capacity to adapt it to address falls prevention (22).

After hospitalisation in an acute geriatric ward, over $11 \%$ of older patients are referred to rehabilitation facilities (23). A recent meta-analysis and systematic literature review of virtual reality rehabilitation (VRR) programmes, demonstrated that VRR programmes are more effective than traditional rehabilitation programmes for physical outcomes (24). Furthermore, other studies have shown that home-based telerehabilitation in older patients with COPD and HF was both feasible and effective (25).

\section{Potential Barriers}

The COVID-19 pandemic has catalysed the rapid adoption of telehealth, and whether healthcare providers are ready or not, the new reality is that virtual care has arrived (26). The advantages of telemedicine can be summarised as the 5 C's: accessible care, increased convenience, enhanced comfort, greater confidentiality, and now reduced risk of contagion (27). Despite this telemedicine has its limitations, including the inability to perform a physical examination and inequitable access to the internet and related technologies for older people which again highlights the need to bridge the "digital divide". Furthermore, effective and efficient integration of telemedicine programmes require extensive staff and patient education, and accessory platforms to facilitate video and audio communications. Comprehensive guides and toolkits can help rapidly integrate telemedicine into practice (28), but for our older patients embracing new technologies it can be a steep learning curve and one could argue are we attempting to "sow a seed and reap a harvest simultaneously?"

For successful implementation of telemedicine globally, it needs to be included in the essential levels 
of care granted to all citizens and countries must adopt the necessary framework of regulations for supporting the wide integration of telemedicine into current health care systems (29). In addition, in the growing age of information technologies, it is imperative patient's information is kept confidential and secure, and that informed consent is obtained. Abiding by guidelines and attention to ethical issues in telemedicine helps to ensure safer use of these services.(30).

If such a remote, tele-healthcare management approach is successful, it should impact positively on health, promote active involvement in decision making, help older patients adopt a healthy lifestyle and outlook, reduce unplanned hospitalisations, and may also herald other novel approaches to managing this vulnerable population.

\section{Summary}

In summary, COVID-19 has resulted in a dramatic change in the way in which we as clinicians provide specialist care which will endure. The aftermath of this pandemic will present an unprecedented challenge in adapting to new modalities for delivering healthcare. Dr. Marjory Warren's identification of the need for interdisciplinary care to older frail people remains relevant today. Addressing the optimal role of technology in the provision of specialist care for older patients can have a positive impact on the future delivery of care to older patients and one's livelihood.

\section{Learning Points}

- The COVID-19 pandemic should act as a catalyst to advance the use of digital technologies for older people.

- Successful remote telemedicine-enhanced initiatives for emergency management of patients, including older ones, have emerged during the pandemic.

- Online community care platforms have been shown to impact positively on the livelihood of older patients, providing an increased sense of well-being and safety whilst improving social cohesion.

- Initiatives such as "tele-geriatric services" should be evaluated as mechanisms to enhance community access to specialist geriatric assessment.

- Existing and experimental models of remote technologically enhanced care in rehabilitation, outpatient (many chronic disease-specific) and residential settings should be trialed for generic older patients.

- Adopting necessary regulatory frameworks for implementing telemedicine services, with attention to ethical issues is imperative for safe use of these services.
Ethical standards: Adhered to high ethical standards.

Conflicts of Interest: No conflict of interest.

\section{References}

1. Gates B. Responding to Covid-19 - A Once-in-a-Century Pandemic? New England Journal of Medicine. 2020;382(18):1677-9.

2. Garnier-Crussard A, Forestier E, Gilbert T, Krolak-Salmon P. Novel Coronavirus (COVID-19) Epidemic: What Are the Risks for Older Patients? J Am Geriatr Soc. 2020;68(5):939-40.

3. St John PD, Hogan DB. The relevance of Marjory Warren's writings today. Gerontologist. 2014;54(1):21-9.

4. Ó Flatharta T, Mulkerrin EC. Back to basics: Giant challenges to addressing Isaac's "Geriatric Giants" post SARS-CoV-2 crisis. The Journal of Nutrition, Health and Aging. 2020;"In-Press".

5. Davidson S. Digital Inclusion Evidence Review 2018: ageuk.org.uk; 2018 [Available from: https://www.ageuk.org.uk/globalassets/age-uk/ documents/reports-and-publications / age_uk_digital_inclusion_evidence_ review_2018.pdf.

6. Vincent C, Reinharz D, Deaudelin I, Garceau M, Talbot LR. Public telesurveillance service for frail elderly living at home, outcomes and cost evolution: a quasi experimental design with two follow-ups. Health Qual Life Outcomes. 2006;4:41.

7. Willard S, Cremers G, Man YP, van Rossum E, Spreeuwenberg M, de Witte L. Development and testing of an online community care platform for frail older adults in the Netherlands: a user-centred design. BMC Geriatr. 2018;18(1):87.

8. Vaportzis E, Clausen MG, Gow AJ. Older Adults Perceptions of Technology and Barriers to Interacting with Tablet Computers: A Focus Group Study. Front Psychol. 2017;8:1687-

9. Grandchildren Ga. Digital Literacy Training for Adults: Initiative, Actors, Strategies. Guidelines Concerning Adult Literacy Teaching Strategies for People Aged Over 55.; 2013.

10. (FDA). FaDA. Developing Software Precertification Program: A Working Model.; 2018

11. Hollander JE, Carr BG. Virtually Perfect? Telemedicine for Covid-19. New England Journal of Medicine. 2020;382(18):1679-81.

12. Langabeer JR, 2nd, Gonzalez M, Alqusairi D, Champagne-Langabeer T, Jackson A, Mikhail J, et al. Telehealth-Enabled Emergency Medical Services Program Reduces Ambulance Transport to Urban Emergency Departments. West J Emerg Med. 2016;17(6):713-20.

13. Salvi F, Morichi V, Grilli A, Giorgi R, De Tommaso G, Dessì-Fulgheri P. The elderly in the emergency department: a critical review of problems and solutions. Intern Emerg Med. 2007;2(4):292-301.

14. Batsis JA, DiMilia PR, Seo LM, Fortuna KL, Kennedy MA, Blunt HB, et al. Effectiveness of Ambulatory Telemedicine Care in Older Adults: A Systematic Review. J Am Geriatr Soc. 2019;67(8):1737-49.

15. Shores MM, Ryan-Dykes P, Williams RM, Mamerto B, Sadak T, Pascualy $\mathrm{M}$, et al. Identifying undiagnosed dementia in residential care veterans: comparing telemedicine to in-person clinical examination. Int J Geriatr Psychiatry. 2004;19(2):101-8.

16. Celler B, Varnfield M, Nepal S, Sparks R, Li J, Jayasena R. Impact of At-Home Telemonitoring on Health Services Expenditure and Hospital Admissions in Patients With Chronic Conditions: Before and After Control Intervention Analysis. JMIR Med Inform. 2017;5(3):e29.

17. Flodgren G, Rachas A, Farmer AJ, Inzitari M, Shepperd S. Interactive telemedicine: effects on professional practice and health care outcomes. Cochrane Database Syst Rev. 2015;2015(9):Cd002098.

18. Lillicrap L, Hunter C, Goldswain P. Improving geriatric care and reducing hospitalisations in regional and remote areas: The benefits of telehealth. J Telemed Telecare. 2019:1357633×19881588.

19. Gilbert AW, Billany JCT, Adam R, Martin L, Tobin R, Bagdai S, et al Rapid implementation of virtual clinics due to COVID-19: report and early evaluation of a quality improvement initiative. BMJ Open Quality. 2020;9(2):e000985.

20. Gallagher J, James S, Keane C, Fitzgerald A, Travers B, Quigley E, et al. Heart Failure Virtual Consultation: bridging the gap of heart failure care in the community - A mixed-methods evaluation. ESC Heart Fail. 2017;4(3):252-8.

21. Bernocchi P, Giordano A, Pintavalle G, Galli T, Ballini Spoglia E, Baratti D, et al. Feasibility and Clinical Efficacy of a Multidisciplinary Home-Telehealth Program to Prevent Falls in Older Adults: A Randomized Controlled Trial. J Am Med Dir Assoc. 2019;20(3):340-6.

22. Mackenzie L, Clifford A. Perceptions of older people in Ireland and Australia about the use of technology to address falls prevention. Ageing and Society. 2020;40(2):369-88

23. Marengoni A, Agüero-Torres H, Timpini A, Cossi S, Fratiglioni L. Rehabilitation and Nursing Home Admission after Hospitalization in Acute Geriatric Patients. Journal of the American Medical Directors Association. 2008;9(4):265-70.

24. Howard MC. A meta-analysis and systematic literature review of virtual reality rehabilitation programs. Computers in Human Behavior. 2017;70:317- 
27.

25. Bernocchi P, Vitacca M, La Rovere MT, Volterrani M, Galli T, Baratti D, et al. Home-based telerehabilitation in older patients with chronic obstructive pulmonary disease and heart failure: a randomised controlled trial. Age Ageing. 2018;47(1):82-8.

26. Wosik J, Fudim M, Cameron B, Gellad ZF, Cho A, Phinney D, et al. Telehealth transformation: COVID-19 and the rise of virtual care. J Am Med Inform Assoc. 2020;27(6):957-62.

27. Dorsey ER, Okun MS, Bloem BR. Care, Convenience, Comfort, Confidentiality, and Contagion: The 5 C's that Will Shape the Future of Telemedicine. J Parkinsons Dis. 2020;10(3):893-7.
28. Smith WR, Atala AJ, Terlecki RP, Kelly EE, Matthews CA. Implementation Guide for Rapid Integration of an Outpatient Telemedicine Program During the COVID-19 Pandemic. J Am Coll Surg. 2020;231(2):216-22.e2.

29. Ohannessian R, Duong TA, Odone A. Global Telemedicine Implementation and Integration Within Health Systems to Fight the COVID-19 Pandemic: A Call to Action. JMIR Public Health Surveill. 2020;6(2):e18810.

30. Langarizadeh M, Moghbeli F, Aliabadi A. Application of Ethics for Providing Telemedicine Services and Information Technology. Med Arch. 2017;71(5):351-5. 